Pacific Journal of Mathematic 


\title{
ON THE VARIATION OF THE BERNSTEIN POLYNOMIALS OF A FUNCTION OF UNBOUNDED VARIATION
}

\author{
Martin Price
}

The behavior of the ordinary Bernstein polynomials, $B_{n} f$, for discontinuous functions $f$ can be quite erratic. The purpose of this note is to give an example of a function $f$ which is quite irregular on the rationals but such that the total variation, $V B_{n} f$ of $B_{n} f$ tends to zero with $n$.

It is known that if $f$ is of bounded variation, then $V B_{n} f$ tends to the variation of $f$ taken over its points of continuity, [2 p. 25]. In [3] we consider arbitrary $f$, and give sufficient conditions for $V B_{n} f$ to tend to zero in terms of the sums $\sum_{r=0}^{n}|f(r / n)|$. It is shown in [2 p. 28] that $B_{n} f$, for unbounded $f$, can behave unusually in terms of pointwise convergence to $f$. Here we construct a function, unbounded on the rationals in every subinterval of $[0,1]$, and which has the property that $B_{n} f$ converges in variation (and uniformly) to zero.

2. Preliminaries. The $n$-th Bernstein polynomial of the real function $f$ on $[0,1]$ is

$$
B_{n} f \equiv \sum_{r=0}^{n} f\left(\frac{r}{n}\right) p_{n r}(x),
$$

where

$$
p_{n r}(x) \equiv\left(\begin{array}{c}
n \\
r
\end{array}\right) x^{r}(1-x)^{n-r}, \quad x \in[0,1] \text {. }
$$

Since $B_{n} f$ depends only on rational values of $f$, we restrict ourselves to " skeletons," i.e., functions defined only on the rationals in $[0,1]$, in the manner of [1]. We need the following facts:

(A) If $r=1, \cdots, n-1$, then for all $n$,

$$
P(n, r) \equiv \operatorname{Max}_{[0,1]} p_{n r}(x)<\mathrm{Cn}^{\frac{1}{2}}[r(n-r)]^{-\frac{1}{2}}
$$

where $C$ is an absolute constant [1].

(B) If $a$ is a positive integer, then

$$
P(a n, a r)<2 a^{-\frac{1}{2}} P(n, r)
$$

for each $n \geqq 2$ and $r=1, \cdots, n-1$. ((A) and (B) are applications of Stirling's formula.)

(C) For all $n$ and $f$ 


$$
V B_{n} f \leqq 2 \sum_{r=0}^{n}\left|f^{\prime}\left(\frac{r}{n}\right)\right| P(n, r)
$$

(D) If $\sum_{i=1}^{\infty} f_{i}$ is a pointwise convergent series of functions (skeletons) on $[0,1]$ then,

$$
V B_{n}\left(\sum_{i=1}^{\infty} f_{i}\right) \leqq \sum_{i=1}^{\infty} V B_{n} f_{i}
$$

where the right side may be $+\infty$.

3. Construction. We define a sequence of skeletons $f_{i}$ such that each skeleton tends to $+\infty$ on a set of rationals tending to a limit rational $r_{i}$. The $r_{i}$ will be dense in $[0,1]$. It is shown that the skeleton $f \equiv \sum_{i=1}^{\infty} f_{i}$ has the following properties:

(1) $f$ is unbounded on the rationals in every subinterval of $[0,1]$;

(2) $V B_{n} f \rightarrow 0$ as $n \rightarrow \infty$.

(Since $f$ will satisfy $f(0)=f(1)=0$, and since $B_{n} f(0)=f(0)$ and $B_{n} f(1)=f(1)$ for all $f$ and $n,(2)$ implies $B_{n} f \rightarrow 0$ uniformly on $[0,1]$.)

For all $i=1,2, \cdots$, pick $r_{i} \equiv p_{i} / q_{i}$ such that $q_{i}$ is prime, $0<p_{i}<q_{i}$, $q_{i}<q_{i+1}$, and $r_{i} \in I_{i}$, where $I_{1}=[0,1 / 2], I_{2}=[1 / 2,1], I_{3}=[0,1 / 4], \cdots I_{6}=$ $[3 / 4,1], I_{7}=[0,1 / 8], \cdots$. Thus the $r_{i}$ are dense in $[0,1]$. Define

$$
f_{i}\left(\frac{p_{i}}{q_{i}}+\frac{1}{q_{i}^{\alpha(i, l)}}\right) \equiv l
$$

where for each $i, \alpha(i, l)$ is a strictly increasing sequence of positive integers to be determined later. For all other rationals in $[0,1]$, put $f_{i} \equiv 0$, and then set $f \equiv \sum_{i=1}^{\infty} f_{i}$. Since the supports of the $f_{i}$ are disjoint, $f$ is well defined at all rationals, and satisfies (1) by construction. We have

$$
V B_{n} f \leqq \sum_{i=1}^{\infty} V B_{n} f_{i} \leqq \sum_{i=1}^{\infty} H(i, n)
$$

by $2(\mathrm{C})$ and (D), where we have put

$$
H(i, n) \equiv 2 \sum_{r=0}^{n}\left|f_{i}\left(\frac{r}{n}\right)\right| P(n, r) \text {. }
$$

Lemma (3.1). For fixed $i$, it is possible to choose $\alpha(i, l), l=1,2, \cdots$ such that

$$
H\left(i, q_{i}^{\alpha(i, l)}\right)<\frac{1}{q_{i}^{2} l}
$$

Proof. To simplify matters, let $p_{\imath} \equiv p, q_{i} \equiv q$ and $\alpha(i, l) \equiv \alpha_{l}$. When $n=q_{i}^{\alpha(i, k)} \equiv q^{\alpha_{k}}$, there are only $k$, nonzero terms on the right 
in (3.3), and these correspond to the points

$$
\frac{r}{n}=\frac{p}{q}+\frac{1}{q^{\alpha_{j}}}=\frac{p q^{\alpha_{k}-1}+q^{\alpha_{k}-\alpha_{j}}}{q^{\alpha_{k}}} \quad(j=1 \cdots k) .
$$

Since the value of $f_{i}$ at the $j$-th point is $j,(3.3)$ becomes

$$
\sum_{j=1}^{k} 2 j P\left(q^{\alpha_{k}}, p q^{\alpha_{k}-1}+q^{\alpha_{k}-\alpha_{j}}\right) .
$$

By applying (2.2), one gets each term in (3.5) less than

$$
\begin{aligned}
& 2 j C\left[\frac{q^{\alpha_{k}}}{\left[p q^{\alpha_{k}-1}+q^{\alpha_{k}-\alpha_{j}}\right]\left[q^{\alpha_{k}}-p q^{\alpha_{k}-1}-q^{\alpha_{k}-\alpha_{j}}\right]}\right]^{\frac{1}{2}} \\
= & 2 j C\left[q^{\alpha_{k}}\left(\frac{p}{q}-\frac{p^{2}}{q^{2}}-\frac{2 p}{q^{\alpha_{j}+1}}+\frac{1}{q^{\alpha_{j}}}-\frac{1}{q^{2 \alpha_{j}}}\right)\right]^{-\frac{1}{2}} .
\end{aligned}
$$

Thus, for $k=j=1, \alpha_{1}$ may be chosen so large that (3.6), hence (3.5), is less than $1 / q^{2}$. (We pick $\alpha_{1} \geqq 2$ so that $p / q+1 / q^{\alpha_{1}}<1$.) Now suppose $\alpha_{k}, k=1, \cdots, l-1$ have been chosen so that $\alpha_{k}>\alpha_{k-1}$, and so that (3.5) is less than $1 / q^{2} k$. When $k=l,(3.6)$ shows that $\alpha_{l}$ can be chosen so that each term, $j=1, \cdots l$ is less than $1 / q^{2} l^{2}$. Thus (3.5) is less than $l \cdot(q l)^{-2}=1 / q^{2} l$.

We can factor every integer $n$ uniquely as:

$$
n \equiv d \cdot \prod_{j=1}^{T} n_{j}, \quad n_{j}=q_{i_{j}}^{\alpha\left(i_{j}, L_{j}\right)} \quad q_{i_{j}}<q_{i_{j+1}} .
$$

The $q_{i_{j}}$ are those $q_{i}$ which appear in $n$ to a power greater than or equal $\alpha\left(i_{j}, 1\right)$, and $L_{j}$ is the largest index $l$ of the exponents $\alpha\left(i_{j}, l\right)$ such that $q_{i_{j}}^{\alpha\left(i_{j}, l\right)}$ divides $n$. For any $n$,

$$
\sum_{i=1}^{\infty} H(i, n)=\sum_{j=1}^{T} H\left(i_{j}, n\right) \leqq \sum_{j=1}^{T} 2\left(\frac{n_{j}}{n}\right)^{\frac{1}{2}} H\left(i_{j}, n_{j}\right)
$$

where the inequality follows from (2. B) with $a=n / n_{j}$. If we apply the lemma to each term, we get the last sum less than

$$
\sum_{\jmath=1}^{T} 2\left(\frac{n_{j}}{n}\right)^{\frac{1}{2}} \frac{1}{q_{i_{j}}^{2} L_{j}} \leqq \frac{2}{n_{T}^{1 / 2}}\left(\sum_{\jmath=1}^{T-1} \frac{1}{q_{i_{j}}^{2} L_{j}}\right)+\frac{1}{q_{i_{T}}^{2} L_{T}}
$$

where the decomposition applies if $T>1$. In this case, the sum on the right is dominated by $\sum 1 / m^{2}$ and is thus bounded. (If $T=1$, the assertion is that (3.9) holds if the sum is regarded as vacuous, and a similar remark holds for (3.11) below.) Therefore if the largest of the $q_{i_{j}}, q_{i_{T}}$ is as large as, let us say, $q_{i_{k}}, n_{T}$ will also be large, and (3.9) can be made less than $\varepsilon$.

Now suppose $n$ is such that every $q_{i_{j}}<q_{i_{*}}$. As before 


$$
\sum_{i=j}^{\infty} H(i, n) \leqq \sum_{j=1}^{T} 2\left(\frac{n_{j}}{n}\right)^{\frac{1}{2}} \frac{1}{q_{i_{j}}^{2} L_{j}} \quad\left(q_{i_{j}}<q_{i_{*}}\right)
$$

Let $k$ be the first index where $\operatorname{Max}_{1 \leqq j \leqq T} L_{j}$ occurs. Then (3.10) becomes

$$
\begin{aligned}
\sum_{j \neq k}\left[2\left(\frac{n_{j}}{n}\right)^{\frac{1}{2}} \cdot \frac{1}{q_{i_{j}}^{2} L_{j}}\right]+\frac{1}{q_{i_{k}}^{2} L_{k}} \leqq \\
\quad\left[2(2)^{-\alpha\left(i_{k}, L_{k}\right) / 2}\left(\sum_{j \neq k} \frac{1}{q_{i_{j}}^{2} L_{j}}\right)\right]+\frac{1}{q_{i_{k}}^{2} L_{k}},
\end{aligned}
$$

since $q_{i_{k}} \geqq 2$ and appears in every $n^{j} / n$ for $j \neq k$. As in (3.9), the sum is bounded. Thus if $L_{k}$ is large enough, say $L_{k} \geqq L, \alpha\left(i_{k}, L_{k}\right)$ is also large, and (3.10) is less than $\varepsilon$.

Now suppose every $q_{i}$ in $n$ is less than $q_{i_{*}}$ and all the indices $L_{j}$ are less than $L$. There are only a finite number of such combinations $\Pi_{j=1}^{T} n_{j}$, and we denote them $C_{s}, s=1 \cdots S$. If $n \equiv d \cdot C_{s}$, we get by (2.B)

$$
\sum_{i=1}^{\infty} H(i, n) \leqq \frac{2}{d^{1 / 2}} \sum_{i=j}^{\infty} H\left(i, C_{s}\right) .
$$

However only a finite number of $q_{i}$ appear in any $C_{s}$ so that the sum is bounded by, say $M_{s}>0$. Therefore (3.12) is less $2 M_{s} / d^{1 / 2}$, and we can pick $d_{s}$ large enough so that $d \geqq d_{s}$ implies (3.12) is less than $\varepsilon$.

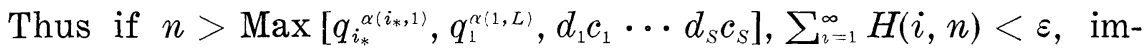
plying $V B_{n} f<\varepsilon$ by $(3.2)$.

\section{BIBLIOGRAPHY}

1. F. Herzog and J.D. Hill, The Bernstein polynomials for discontinuous functions, Amer. J. Math. 68 (1946), 109-124.

2. G.G. Lorentz, Bernstein Polonomials, University of Toronto Press, 1953.

3. M. Price, Variation convergence for Bernstein polynomials, Proc. Amer. Math. Soc. 19 (1968), 551-554.

Received May 22, 1967. This is based on part of the author's Ph. D. thesis at Purdue University, written under the direction of Professor C. Goffman. It was supported by NSF Grant GP-03515.

Wayne State University 


\section{PACIFIC JOURNAL OF MATHEMATICS}

EDITORS

H. ROYDEN

Stanford University

Stanford, California

R. R. Phelps

University of Washington

Seattle, Washington 98105
J. DugundJI

Department of Mathematics

University of Southern California

Los Angeles, California 90007

\section{RICHARD ARENS}

University of California

Los Angeles, California 90024

\section{ASSOCIATE EDITORS}
E. F. BeCKENBACH
B. H. NeUmanN
F. WOLF
K. YOSIDA

\section{SUPPORTING INSTITUTIONS}

UNIVERSITY OF BRITISH COLUMBIA CALIFORNIA INSTITUTE OF TECHNOLOGY UNIVERSITY OF CALIFORNIA MONTANA STATE UNIVERSITY UNIVERSITY OF NEVADA NEW MEXICO STATE UNIVERSITY OREGON STATE UNIVERSITY UNIVERSITY OF OREGON OSAKA UNIVERSITY UNIVERSITY OF SOUTHERN CALIFORNIA
STANFORD UNIVERSITY UNIVERSITY OF TOKYO UNIVERSITY OF UTAH WASHINGTON STATE UNIVERSITY UNIVERSITY OF WASHINGTON

AMERICAN MATHEMATICAL SOCIETY CHEVRON RESEARCH CORPORATION TRW SYSTEMS NAVAL WEAPONS CENTER 


\section{Pacific Journal of Mathematics \\ Vol. 27, No. $1 \quad$ January, 1968}

Willard Ellis Baxter, On rings with proper involution ............... 1

Donald John Charles Bures, Tensor products of $W^{*}$-algebras........... 13

James Calvert, Integral inequalities involving second order derivatives . . . . 39

Edward Dewey Davis, Further remarks on ideals of the principal class.... 49

Le Baron O. Ferguson, Uniform approximation by polynomials with integral

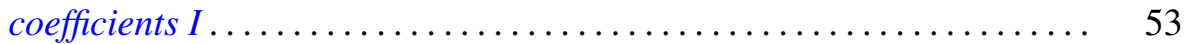

Francis James Flanigan, Algebraic geography: Varieties of structure

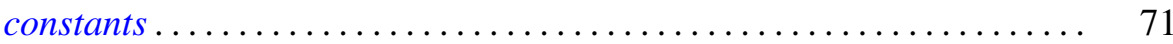

Denis Ragan Floyd, On QF -1 algebras ..................... 81

David Scott Geiger, Closed systems of functions and predicates ......... 95

Delma Joseph Hebert, Jr. and Howard E. Lacey, On supports of regular Borel measures ................................... 101

Martin Edward Price, On the variation of the Bernstein polynomials of a function of unbounded variation ........................ 119

Louise Arakelian Raphael, On a characterization of infinite complex matrices mapping the space of analytic sequences into itself........ 123

Louis Jackson Ratliff, Jr., A characterization of analytically unramified

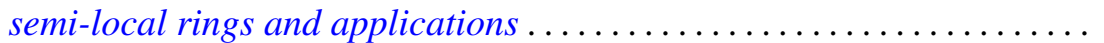

S. A. E. Sherif, A Tauberian relation between the Borel and the Lototsky transforms of series ................................ 145

Robert C. Sine, Geometric theory of a single Markov operator .......... 155

Armond E. Spencer, Maximal nonnormal chains in finite groups......... 167

Li Pi Su, Algebraic properties of certain rings of continuous functions .... 175

G. P. Szegô, A theorem of Rolle's type in $E^{n}$ for functions of the class $C^{1} \ldots 193$

Giovanni Viglino, A co-topological application to minimal spaces ........ 197

B. R. Wenner, Dimension on boundaries of $\varepsilon$-spheres ............... 201 